\title{
Aproximación a la magia, la brujería y la superstición en la antigüedad
}

\author{
ANA M. ${ }^{a}$ VAzQuez HoYs *
}

\section{INTRODUCCIÓN}

Recientes obras en campos tan dispares como la antropologia, el folklore y las religiones comparadas han demostrado la necesidad de mirar con ojos nuevos las antiguas costumbres y creencias relacionadas con la magia.

Pero dar una definición acertada de lo que es la magia es algo que no resulta fácil. Hoy en día el hombre medio parece haber perdido la clave de su propio ser; el denominador común de credo y ritual, que en otro tiempo vinculaba a los hombres entre sí, ha perdido su fuerza. Mientras que en los tiempos antiguos la magia, el rito y la religión suministraban al hombre una coraza espiritual contra el entorno hostil, el hombre moderno se deja llevar por otra clase de creencias, abocado al materialismo. El estudio de aquellas ceremonias, ritos y prácticas de nuestros antepasados, ejecutadas por medio de ritos mágicos, será el objeto de este trabajo, que procuraremos llevar a cabo con el mayor rigor posible, dado el recelo que estos estudios pueden (y suelen) suscitar, debido a la pretendida vulgarización y proliferación actual de los usos mágicos y

* Profesora Titular. Departamento de Prehistoria e H. ${ }^{a}$ Antigua. UNED. Madrid. Este es el primero de una serie de articulos sobre el tema de la Magia en la Antigüedad, que pensamos publicar en esta revista. Dado que los trabajos no pueden superar un cierto número de páginas, completaremos esta introducción en sucesivos números con otros trabajos sobre el tema. 
astrológicos, aprovechándose los "magos" actuales de la eterna credulidad de la raza humana, siempre dispuesta a llenar con prodigios su imaginación y con una respuesta inmediata sus íntimos deseos. El ser humano permanece a través de los tiempos. Y con él, la imperiosa necesidad de protegerse contra las fuerzas maléficas y de atraerse las benéficas. Esta necesidad podría ser, en opinión de diversos autores, el origen de la magia. Pero, esta proliferación de "detestables charlatanes", como los define Cumont, no es nueva. Ya en el siglo ॥ de nuestra Era, Vettius Valens se quejaba de los que se erigían en profetas, sin la larga preparación necesaria, convirtiendo en ridícula u odiosa la ciencia que osaban invocar ${ }^{1}$.

Comenzaremos nuestro estudio por algunas cuestiones previas: Qué significa la palabra "Magia", qué se entiende por tal y algunas ciencias o disciplinas que tienen relación con ella, continuando por el análisis de las prácticas más comunes de magia y brujería que conocemos dentro del ámbito cronológico de la Historia Antigua, tales como la magia del nombre, el sonido, las ataduras, clavos y nudos mágicos, los espejos y la inversión de la imagen, las tabellae defixionum, etc..

\section{SIGNIFICADO DE LA PALABRA MAGIA}

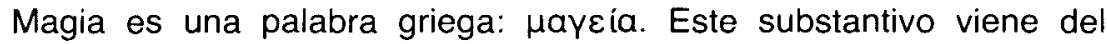
adjetivo $\mu a ́ y o s$, ou, que, en griego, reproducía un vocablo persa cuya consonancia era casi idéntica. El latín lo tradujo por magus y Cicerón la emplea para designar a los sabios persas.

La raíz de esta palabra es MAG, en hebreo. De una manera general, significa "formar» o «modelar», evocando también el sentido de «maceración". Esto hace pensar que tal vez los antiguos magos se dedicaban a amasar polvos o productos análogos a la harina de trigo, y también, sin duda, a la fabricación de drogas con productos macerados en los

' Vettius Valens, V, 12, cit. por Cumont, F., Les religions orientales dan le paganisme romain. Paris 1929, pág. 157. 
líquidos $^{2}$. En su empleo más restringido, en el mundo clásico, magia es la ciencia, la industria y la religión de los Magos, los sacerdotes de la secta de Zoroastro importados a Grecia.

\section{QUÉ SE ENTIENDE POR MAGIA}

Partimos de la base de que la magia es una ciencia. Ésta, al igual que la astrología, parte de la concepción fundamental de que existe en la naturaleza un orden y unas leyes y que la misma causa produce siempre el mismo efecto. El ser humano es religioso y mágico a la vez, en lo más profundo de sí mismo. Las ideas mágicas tienen su punto de partida en una serie ilimitada de observaciones exactas. En el estadio de vida primitiva, en la pesca y en la caza, el hombre estaba en un contacto

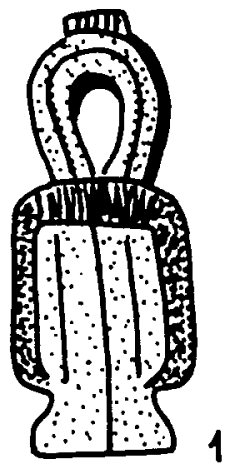

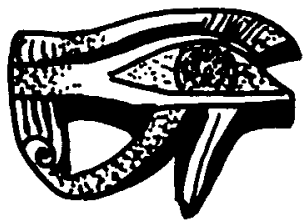

2

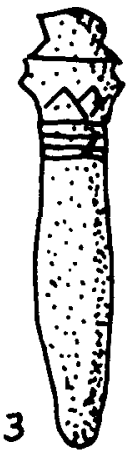

Fig. 1. Amuletos egipcios. 1. Nudo de Isis. 2. Ojo "Oudjat", compuesto, del dios celeste, significa la visión total, la plenitud fisica y la fecundidad Universal. 3. El papiro, signo de verdor.

2 PIOBB, obra citada en nota 3, infra, pág. 32. Sobre las drogas en la Antigüedad cfr. Gonzalez WAGNeR, C., "Psicoactivos, misticismo y religión en el mundo antiguo", Gerión 2, 1984, págs. 31-59; HARNER, M. J. ed., Hallucinogens and shamanism. Oxford University Press, Nueva York 1973. También sobre el uso de drogas y la brujeria cfr. ConkLIN, G. N., "Alkaloids and the witches sabbat" en American Journal of Pharmacy and Sciences 130, 1958. págs. 171-174. Propiamente la palabra irania "maga" "poder mágico de los magos", al. "mögen", gr. "mēchar", "méchos", "remedio". Cfr. CARNOY en "Les noms grecs des devins et magiciens", LEC XXIV, 1956, págs. 97-106, cit. por GIL, L. Therapeia, Madrid 1969. pág. 91 , nota 3 , en pág. 470. 
más intimo con la naturaleza que un hombre civilizado. Su atención, fija en un mismo punto, a veces durante largas horas de acecho, pudo conducirle a certidumbres, mil veces comprobadas, referentes a las fuerzas a las que obedecen los demás seres: el poder de la mirada que fascina, el del canto que apacigua a un toro, que duerme a un niño o que vuelve inofensiva a la serpiente. Llegando a la convicción de que existian en la naturaleza fuerzas escondidas, a las que se conocen por el nombre de “fluidos». Estos fluidos, según Piobb ${ }^{3}$, son de tres naturalezas:

- Magnética y puramente terrestre.

- Vital y principalmente humana.

- Esencial y generalmente cósmica.

A medida que iba evolucionando, la magia se ayudaba de técnicas cada vez más prácticas, de las que en realidad podía depender la eficacia de los ritos. Lo que son los fluidos magnéticos no necesita explicación aqui. La Física moderna se sirve de ellos de una forma mucho más completa de la que se podian servir los Magos de la India o de Persia. $Y$ este es solo uno de los múltiples fenómenos de la naturaleza que los practicantes de la magia supieron aprovechar.

Los fluidos vitales son aquellos a los que hay que atribuir los fenómenos del psiquismo, es decir, las manifestaciones misteriosas e hiperfisicas del Ser, una fuerza vital del ser humano, más allá de las formas conocidas de energía, a la que Paracelso llamaba spiritus vitae.

En cuanto a los fluidos esenciales o cósmicos, son de un orden más elevado y varian de nombre dependiendo de la forma en que los diferentes pueblos los han presentado, a menudo guardados por y para un pequeño número de iniciados y conservados casi secretos. La ceremonia oculta, que se realizaba con el mayor cuidado, debería tener siempre el resultado apetecido. Solo era necesario conocer la afinidades misteriosas que unian a todos los seres para poner en movimiento los mecanismos del universo.

Asi pués, podemos decir que la magia utiliza fuerzas naturales, del propio hombre, de la naturaleza y los fluidos terrestres y estelares, dando lugar a la "Magia macrocósmica" y a la "Magia microcósmica", ejerciéndola de dos formas esenciales, la "personal», cuando el fenómeno 13.

Pıвв, P. V., Formulaire de Haute Magie. St. Jean de Braye, Ed. Dangles, 1984, pág 
se opera sin la ayuda de un rito exterior y la "ceremonial» cuando sí lo hace.

Y será de este segundo modo como la Magia entre en el dominio de las religiones, hasta el punto de que la religión, en sus manifestaciones exteriores, no es muy diferente de la magia ceremonial.

Quien se pregunte qué es la magia, o mejor aún, qué se entiende por magia en las diferentes culturas, debe tener en cuenta varias ciencias, tanto la antropología cultural como la etnología, que tienen sobre el historiador la ventaja de la "presencia" actual del objeto de su estudio, el poder comparar entre sí series de mitos, ritos y usos, extraidos de las culturas actuales, estudiar sus variantes y buscar sus estructuras básicas. El historiador, en cambio, estudia una sociedad definida, encerrada en un ámbito espacio-temporal bien delimitado. $Y$ debe tener en cuenta que dicha sociedad nunca es una sociedad cerrada, que las influencias exteriores deben ser identificadas y evaluadas constantemente, absorbidas $y$ estratificadas. $Y$ debe aprender el dinamismo concreto del mundo que estudia, preguntándose las causas y el por qué de ellas, así como los mecanismos internos. Todo esto sin olvidar que la magia es, en sí, un elemento profundamente conservador ${ }^{4}$ y a lo largo de la Historia lo que ha cambiado es más el concepto que la sociedad tiene de la magia que las mismas prácticas mágicas. Asi, mientras que en la Edad Media se era acusado de magia cuando se establecía una actuación por medios diabólicos, en el siglo xx, como dice Piobb ${ }^{5}$ uno se puede encontrar acusado de magia cuando se esfuerza, a través de medios llamados "sobrenaturales", en llegar a unos resultados imposibles de conseguir de otra forma.

Pero, a lo largo de los tiempos, la opinión sobre la Magia ha variado, y como hemos visto, también su definición. Para unos autores, Magia es la posibilidad de obrar por medio de ritos, cuya revelación, en la Antigüedad, era atribuida a los dioses, sobre los seres visibles o invisibles de la tierra y de las aguas, de los abismos y del cielo ${ }^{6}$.

Según algunos, la magia comprende todas las artes y ciencias ocultas, las supersticiones y el folklore. Otros, en fin, la definen como una

${ }^{4}$ Festugière. La révelation d'Hermès Trismégiste I, cap. VIII, pág. 283.

PIOBB, P. V., Obra citada, Introduction.

${ }^{6}$ Buisson, M. La Magia. Paris 1958. Barcelona, 2. ${ }^{a}$ ed. 1976, pág. 12. En general, Sella, P., Magia: Studi di storia delle religioni in memoria di Raffaela Garosi. Rome Ed. Bulzoni, 1976; También Textos de magia en papiros griego. Ed. Gredos. Biblioteca Clásica Gredos núm. 105. Introducción, traducción y notas de Calvo Martínez, J. L. y Sánchez Romero, M. ${ }^{a}$ D.. Madrid 1987. 
técnica fundamentada en la creencia en unos poderes localizados en el alma humana y en el universo externo o interno, una técnica que tiende a imponer el deseo humano de dominar sobre la naturaleza o sobre los principios mismos del ser humano, utilizando poderes sobrenaturales. Pero también puede ser considerada como una creencia fundamentada en los ilimitados poderes del alma. La multitud de todos esos poderes, posiblemente, pueden reducirse a una única noción de "poder» o "mana". El equivalente, o los equivalentes griegos de esta palabra, hallado en textos helenísticos, puede ser dynamis, "poder", charis, "gracia", y areté, "eficacia». Este "mana» mágico se puede utilizar libremente. Necesita solo un "canal» y el verdadero mago es solo su medium, un transmisor, cuyas ropas o todo lo que toca pueden recibir y almacenar el «mana»?

Para Bouché-Leclercq ${ }^{8}$, la magia es distinta de la adivinación o mántica y es preciso separarlas, aunque a veces una esté ligada a la otra, ya que están estrechamente unidas en su principio.

La adivinación es, para este autor, la penetración del pensamiento divino por la inteligencia humana, siendo su dominio todo lo que el espíritu humano no puede conocer por sus solas fuerzas, en primer lugar el

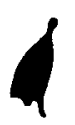

1

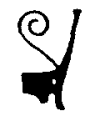

2

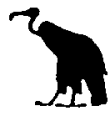

3

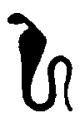

4

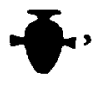

5

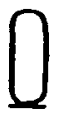

6

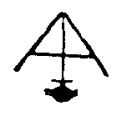

7

Fig. 2. 4 Amuletos egipcios que confieren la fuerza sobrehumana al Faraón. 1. Corona del Alto Egipto. 2. Corona del Bajo Egipto. 3. La diosa-buitre. 4. La diosa-cobra. 5. Amuleto que confiere la consciencia (literalmente el corazón). 6. Amuleto que confiere el poder de vuestras manos o vuestras piernas o vuestro nombre (el cartucho). 7. El compás del albañil garantiza la estabilidad perpetua.

7 Luck, G., Arcana Mundi. Magic and the Occult in the Greek and Roman Worlds. A collection of Ancient Texts, translated, annoteated and Introduced by, Baltimore-London, 1985, "Magic", Introduction, pág. 3.

\& Bouche-Leclerco, A.. Histoire de la divination dans l'antiquité, París 1879, reimp. Germany, 1978, tomo I, págs. 7-13; también sobre este tema cfr. EHNMARK, E., “Religión and magic-Frazer, Soderblom and Hagerstrom". Ethnos 21, 1956, págs. 1-10; GEERTZ, H.: "An anthropology of religion and magic 1 , Journal of Interdisciplinary History VI, verano 1975, págs. $71-89$. 
porvenir, luego el pasado y también el presente. La magia es el arte de producir efectos contrarios a las leyes de la naturaleza.

Pero es bién sabido que un gran número de métodos adivinatorios consisten en la interpretación de efectos maravillosos producidos antes por recetas mágicas. $Y$ es la magia la que proporciona el tema sobre el que se ejerce la penetración mántica.

Pongamos como ejemplo el caso de la adivinación por medio de las piedras preciosas o «litomancia», que el mismo autor trata algo más adelante $^{9}$, o la "lecanomancia» o adivinación por medio de un espejo mágico, que veremos más abajo.

Se puede decir, generalizando, que hay un elemento mágico en toda ceremonia o práctica destinada a preparar o producir un efecto adivinatorio. Y no queda a la adivinación propiamente dicha más que la observación de los signos fortuitos, sobre los que la voluntad humana no puede ejercer ninguna influencia.

Como la magia sirve de auxiliar y de vehículo a la adivinación, ella, a su vez, aclara la magia y la ayuda a perfeccionar sus métodos. $Y$ existe toda una rama de la adivinación, la «jatromántica" o mántica aplicada a la medicina, que no es otra cosa que una mezcla, en proporciones variables, de adivinación y magia. Los remedios descubiertos por esta adivinación eran verdaderas recetas mágicas, y los maestros en tal arte sabian que les estaba prohibido resucitar a los muertos, pero que no era para ellos una cosa imposible ${ }^{10}$. Reinach, a su vez, definió la magia como la "estrategia del animismo ${ }^{11}$.

Magia, en fin, es, para P. V. Piobb, el medio por el que el ingenio humano se sirve para disponer, en la medida que lo permiten sus posibilidades, de las energías existentes, sea cual sea la forma en que estén en el Universo ${ }^{12}$.

9 BOUCHÉ-LECLERCQ, Obra citada. tomo I, págs. 183-184.

${ }^{10}$ BOUCHÉ-LeCleRCQ, Obra citada, I, págs. 11-12.

"REINACH, S., Cultes, mythes et religions, II, Intr. pág. XV.

${ }^{12}$ PIOBв P.V., Formulaire de Haute-Maqie, St. Jean de Braye, Editions Dangles, 1984 pág. 19. Una importante influencia en el renovado interés por la magia greco-romana se debe a la revisión y publicación del Corpus de papiros mágicos greco-egipcios por Preisendanz, en dos volúmenes (1928 y 1931), edición corregida y aumentada con el añadido de material suplementario en la segunda edición, “Papyri Graecae Magicae: Die griechischen Zauberpapyri" (PGM), ed. A. HENRichS, I., Stuttgart, 1973, II, Stuttgart, 1974. Trad. española cit. en nota 6, supra Aún más impulsó estos estudios la publicación por M. MARGALIOTH de "Sepher ha-Razim" (Libro de los Misterios), Jerusalem, 1966, que es aparentemente un manual de magia judía, datado por Margalioth en el siglo III d. C., traducido al inglés por 


\section{MAGIA Y ARTE}

Solo S. Reinach, en pleno auge de la interpretación materialista sobre sus orígenes, se atrevió a refutar la reiterada opinión de que el arte era meramente un pasatiempo o entretenimiento, situando sus orígenes en el rito y la magia. En su ensayo, titulado L'art et la magie, influenciado por J. G. Frazer, B. Spencer y F. J. Guillen, liga el impulso principal de su nacimiento en la "edad del reno", al desarrollo de la magia, aludiendo a ciertas tallas de pequeños fragmentos de hueso que muestran cabezas de caballo desolladas, que para él servían de amuleto para atraer a otros caballos a las proximidades de la caverna, dado que en la Prehistoria, con el pensamiento del hombre centrado en su relación con fuerzas invisibles, el impulso más hondo a la creación artística residía para él en los poderes de la magia, donde el arte se convertía en el auxiliar más precioso del hombre ${ }^{13}$. Primero como abstracción que puede adoptar la forma de un signo repleto de significado simbólico especial, de caracter mágico o sagrado, que han utilizado todas las religiones, cuando trataban de exorcizar los poderes hostiles, luego utilizando figuras de animales: el caballo, el elefante, la serpiente, los ciervos, etc...

Ya el hombre auriñaciense entraba en posesión mágica de los animales que trataba de cazar o de vencer, dibujando sus contornos en la obscuridad de las cavernas, a la escasa luz de las antorchas. A lo largo de un dilatadísimo período de tiempo, el hombre sólo supo expresar objetos por medio de contornos simples. Por ello resulta aún más asombroso que pudiera plasmar imágenes forjadas por su imaginación. Estas primeras fantasías rituales nacieron, sin duda, con el deseo de establecer alguna relación con lo invisible, deseo que debió ser ardiente para producir tal abundancia de símbolos, compuestos híbridos o imágenes mezcla de animal y hombre.

Michael Morgan, publicado por Scholar Press. La edición de Margalioth ha sido muy criticada por I. Grünwald.

Otros estudios secundarios sobre la magia greco-romana, aparecidos recientemente son los de SMITH, M., Clement of Alexandria and a Secret Gospel of Mark, Cambridge, Mass. 1973; HuLls, J. M. Hellenistic Magic and the Synoptic Tradition, London 1974, que discute la naturaleza y caracteristicas de la magia greco-romana, constituyendo un serio estudio sobre esta materia; AUNE, David E., "Magic in Early Christianity", Aufstieg und Niedergang der Römischen Welt (ANRW) II, 23. 2. Berlin 1980, págs. 1507-1557; Sobre la magia romana cfr. TUPET, A. M. ${ }^{a}$ : «Rites magiques dans l'antiquité romaine" ANRW II, 3 , 16.

${ }^{13}$ Giedion, S., El presente eterno: Los comienzos del arte. Ed. Alianza, 1981, pág. 27. 


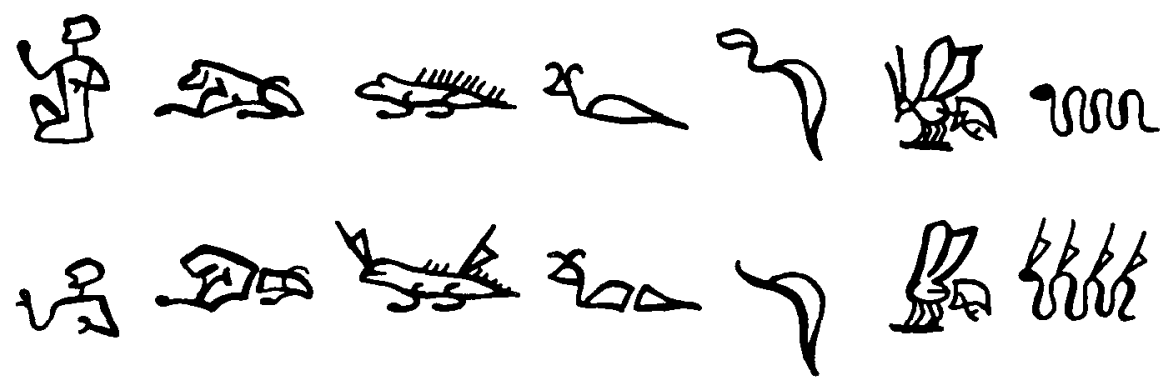

Fig. 3. Jeroglificos embrujados. Arriba: Jeroglificos normales Abajo: Jeroglíficos cortados (sg. François Lexa, La magie dans l'Egypte antique. París 1924). Se corta a los animales o a los enemigos para evitar que hagan daño, muestra evidente del valor atribuido a la imagen.

\section{MAGIA Y RELIGIÓN}

¿Se puede hacer una clara distinción entre religión y magia? Se han intentado muchas aproximaciones al problema, pero ninguna parece ser la correcta para los mismos autores. En general, podemos decir que se han discutido, en diversas obras, por diferentes estudiosos, cuatro posiciones fundamentales:

1. La magia se convierte en religión (K. T. Preuss).

2. La religión intenta reconciliar poderes personales después que la magia ha fallado (Sir James Frazer).

3. Religión y magia tienen raíces comunes (R. R. Marrett).

4. La magia es una forma degenerada de religión (P. Wilhem Schmidt).

Es bien sabido que una persona religiosa reza a unas divinidades de una forma humilde y sumisa, mientras que el mago obliga a esos mismos dioses por medio de amenazas. La persona religiosa confía en la bondad de los dioses, mientras que el mago utiliza algunos conocimientos especiales que le dan poder sobre ellos (algunas veces conoce el nombre secreto, al que responde un demonio). La religión, en cambio, se dirige a la divinidad mediante la plegaria, mientras la magia conmina a la divinidad a ayudarla. El sacerdote «ruega». El mago «impone», "ordena». 
Aquél "sirve" a la divinidad, éste "se sirve" de la divinidad, pasando los límites de respeto, temor y consideración impuestos por la religión ${ }^{14}$.

Estas premisas suelen o pueden ser generalmente verdad, e incluso encontramos un talante «religioso" en algunos textos mágicos, como vemos en Egipto en el Papiro Mágico de Leiden ${ }^{15}$.

"Yo te invoco, tú que eres el más grande, que has creado todo, tú, el que se ha creado a sí mismo, que ves todas las cosas pero no puedes ser visto. Tu has dado al sol toda su gloria y poder, tú has situado a la luna en el cielo...

Todas las cosas están sujetas a ti y ninguno de los dioses puede ver tu verdadera forma. Tú puedes transformarte a ti mismo en todo lo que puede ser. Tú eres el invisible Aion de Aion « (PGM 2:89-90).

El mago usa también rituales y liturgias como los que se utilizaban en las grandes religiones del pasado o del presente.

Lo que concierne y concernia al sacerdote y mago era lo mismo; Salud, riqueza, amor, buenas miradas, protección contra peligros o desastres etc...

Apuleyo, en el siglo II d.C. define al mago como "aquél que por su capacidad de hablar con los dioses inmortales tiene poder en todo lo que quiere por la fuerza increible de sus ensalmos" (Magus est, qui communione loquendi cum dis inmortalibus ad omnia, quae velit, incredibili quadam vi cantaminum polleat. Apol. 26) ${ }^{16}$.

Para el mago, sin embargo, hay algo como la "magia negra" (0 "Goética", del griego goáo, yoáw, yoú (gemir), que persigue el mal de la persona a la que desea encantar (Opuesta a la «magia blanca» que busca efectos extraordinarios sin hacer daño), considerando casi por de-

14 de Ruggiero, E., Cardinali, G., Dizionario epigráfico di Antichitá romane I (1886), II (1910), III (1922), IV (1929) y a partir de 1946, t. II 2-3, 1959, s. v. magia. VieRre, S., L'image et la pensée dans la Métamorphoses d'Ovide. París, 1964, pág. 153 y ss; MASSON. NEAU, E., La magia dans l'Antiquité romaine. Paris, 1934; MAC Mullen, R., Ennemies of the Roman order. Treason, Unrest and Alienation in the Empire. Harv. Univ. Press 1966; AN. NEOUIN, J., Recherches sur l'action magique et ses representations (le. et lle siècles après (J.C.). París, 1973; Scullard, H.H., Festivals and Ceremonies of the Roman Republic. London, 1981, pág. 15, 75, 128. BAYET, J., «La croyance romaine aux présages déterminants: Aspect litteraires et chronologie", Col Latomus // (Hom. a J. Bidez et F. Cumont). Bruxeiles.

${ }^{15}$ Luck, G., Arcana Mundi. Magic and the Occult in the Greek and Roman Worlds cit. en nota 7, supra, 100.

${ }^{16}$ GIl, L., Therapeia. La medicina popular en el mundo clásico. Madrid, Ed. Guadarrama, 1969, pág. 224. 
finición que la religión por sí misma no puede hacer daño. Sin embargo, las amenazas de los dioses no son desconocidas en contexto religioso. Y así, cuando Germánico, el hijo adoptivo del emperador Tiberio (no muy querido por su padre adoptivo), muere, las circunstancias no muy claras del hecho provocaron reacciones en el pueblo romano. Entre los años 69-73, el historiador Tácito ${ }^{17}$ no excluía que fuese causada por operaciones mágicas y cuando las gentes de Roma oyeron las noticias, irrumpieron en los templos y echaron las estatuas de los dioses a la calle a puntapiés ${ }^{18}$.

De la misma forma, en tiempos más recientes, los pescadores italianos, trataban las estatuas de sus santos de la misma forma. Cuando tenían una buena pesca, ofrecían a los santos el típíco incienso, flores y velas, pero cuando la pesca no era buena, maldecian y echaban a puntapiés a los santos de las iglesias.

La ley de la "simpatía" es, en efecto, como veremos más abajo, que si tú das puntapiés a la estatua de su santo o dios, él sentirá de alguna manera el dolor y reaccionará ${ }^{19}$.

Por tanto, algunos estudiosos creen que no hay diferencia fundamental entre religión y magia ${ }^{20}$.

Pero, según algunos autores, si que puede haber alguna: Rezar por algo, dar gracias por algo, es también concebible en magia, y algo natural en la religión, pero no existe en magia la conciencia de pecado y el rezar a los dioses pidiendo perdón ${ }^{21}$.

17 TaCito, Anales, libro II, pág. 97. Ed. introducción y notas de P. J. Quetglas Trad. de Carlos Coloma, Barcelona, Ed. Planeta, 1986, pág. 97, "la enfermedad en que Germánico habia recaido, cuya virulencia era fieramente acrecentada por persuadirse a que habia sido atosigado por Pisón; en cuya prueba se hallaban en el suelo y en las paredes osamentas y reliquias de cuerpos humanos, versos, conjuros, el nombre de Germánico esculpido en planchas de plomo, cenizas medio quemadas mezcladas con sangraza podrida y otras muchas suertes de hechicerías por las cuales se cree ofrecer las almas a los dioses infernales".

${ }_{18}$ TACito Anales, libro II, 82, ed. cit. supra, pág. 102 «desquician las puertas de los templos»; también SUE, Calig. 5.

${ }_{19}$ Ehnmark, R., Ethnos 21, 1956, 1; También Goodenough, E. R., Jewish Symbols in the graeco-Roman Period, 13 vols. New York, Pantheon Books, 1963-68, t. II pág. 155.

${ }_{20}$ Sobre las religiones primitivas cfr. Evans PRITCHARD, E. E., Las teorias de la religión primitiva. Ed. Siglo $\times x \mid, 4{ }^{a}$ ed. en castellano, Madrid, 1984. Vease un resumen reciente sobre esta problemática en QUAIFE G. R., Magia y maleficio. Las brujas y el fanatismo religioso. Ed. Crítica, Barcelona 1989, pág. 48, n. 1, con abundante bibliografia, n. 2; tambièn pág. 50, ก. 3 .

${ }^{21}$ Smith, S., Jesus the Magician, New York, Harper, 1978, pág. 1 passim. 

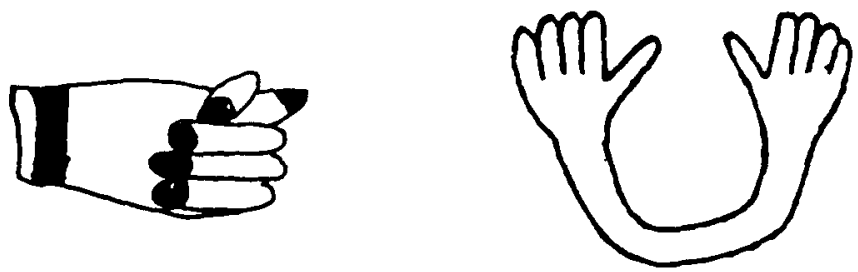

Fig. 4. A. Mano izquierda mágica de defensa egipcia haciendo la "higa". $B$. Jeroglífico temprano egipcio del $\mathrm{ka}$.

El mago no reconoce el pecado. Él está, en cierto modo, por encima de la moralidad y de la ley, tiene una ley para sí mismo. En una sociedad en la que prácticamente todos creian en la magia y la practicaban de una forma u otra, este desprecio por la moralidad convencional y las leyes del Estado podía haber impulsado el comportamiento criminal, pero las razones por las que magos y astrólogos (incluso filósofos) eran periódicamente discriminados en el tiempo del imperio eran, principalmente, de tipo político. En cuanto a la fe, recordemos lo que, hablando de la astrologia en la antigüedad dice Cumont ${ }^{22}$ : "Lo que hacía a la astrología invulnerable a los golpes que le daban la razón y el sentido común, es que era, a pesar del rigor aparente de sus cálculos y sus teoremas, una FE. No solamente implicaba una creencia en postulados indemostrables, sino que había nacido y crecido en los templos de los Caldeos, después en Egipto e incluso en Occidente y no olvidó jamás sus orígenes sacerdotales y solo se separó a medias de la religión que la había engendrado". Y esta FE en los ritos mágicos, que encontramos no solamente en la Antigüedad sino también en nuestros días, es inherente al hombre cuando ejerce un rito, mágico o religioso. $Y$ de "fe" se puede hablar, tanto en la religión cristiana como en cualquier religión, antigua o moderna. Siempre que una persona reza, implora, ora, ruega o intenta influir de alguna manera en las potencias divinas, es porque cree en ellas.

Aunque la magia se halla fundida y amalgamada con la religión en muchos países y edades, hay, según Frazer, fundamentos para pensar

${ }^{22}$ Cumont, F., Les religiones orientales daus le paganisme romain. Paris 1929, pág 158: Contra algunas opiniones de quienes piensan que la fe es exclusiva del Cristianismo y de la "modernidad", cuando nos hemos referido a ella a propósito de los fieles hispanorromanos, cfr. VAZQUEZ HoYS, A.M. ${ }^{a}$, "Algunas consideraciones sobre cultos locales en la Hispania romana", Memorias de $H^{a}$ Antigua 5, Oviedo 1981, pág. 43. creemos que esta fé es el fundamento de toda religión, antigua o moderna. $Y$ por tanto, no exclusiva del Cristianismo, que no es más que una religión helenística, que descansa, entre otras, sobre la base de la fe en el Señor Jesús y del culto al Señor Jesús. Cfr. Guignebert, Ch., El Cristianismo antiguo. Ed. Fondo de Cultura Económica. México, 2. reimp. 1975, pág. 95. 
que esta fusión no es primitiva y que hubo un tiempo en el que el hombre recurrió a la magia sólo para satisfacer las necesidades que excedian a sus inmediatos deseos animales ${ }^{23}$. La consideración de las nociones mágicas y religiosas fundamentales puede inclinarnos a deducir que la magia es más antigua que la religión en la historia de la humanidad. Para Frazer, "la magia no es más que la equivocada aplicación de los más simples y elementales procesos de la inteligencia, es decir, la asociación de ideas en virtud del parecido o la contigüidad, y la religión presupone la acción de agentes personales y conscientes, superiores al hombre, tras del telón visible de la naturaleza» ${ }^{24}$.

Tal vez, debido a la mayor complejidad del proceso religioso, según este autor, la magia pudo preceder a la religión en la evolución de nuestra raza y el hombre intentase sujetar la naturaleza a sus deseos por la fuerza cabal de sus conjuros y encantamientos antes de esforzarse en apaciguar a una divinidad por medio de oraciones y sacrificios.

Para Cumont ${ }^{25}$, la magia y la astrología tuvieron un origen religioso, y la magia quedó siempre como una "hermana bastarda de la religión". Magia y astrología crecieron juntas en los templos de Oriente. Sus prácticas formaron parte del saber equivoco de los encantadores y fabricantes de amuletos que pretendian, por medio de ritos conocidos sólo por ellos, actuar sobre los espiritus que poblaban la naturaleza.

Entre otros autores actuales, Dupuis ${ }^{26}$, piensa que, cuando se quiere hablar de la vida religiosa de las sociedades neolíticas, hay que evitar la confusión constante que se hace entre "religión" y "magia". Para este autor, los pueblos primitivos no tenían una clara noción de lo que nosotros llamamos religión. Para ellos, ésta no era más que una parte integrante de un saber total que no discriminaba lo que podriamos llamar «el complejo religión-magia-tecnologia». En estas sociedades neolíticas, la religión se confundía con la magia. Y la magia era una parte esencial de la tecnología, que permitía ejercer una acción sobre el entorno.

${ }^{23}$ Frazer, J. G., La rama dorada. 10. ${ }^{2}$ Ed. española, FCE España SA, Madrid 1984, pág. 81.

${ }^{24}$ Frazer, Obra citada, pág 81.

${ }^{25}$ Cumont, F. Rel.or., citadas, pág. 171.

${ }^{26}$ Dupuis, J.: Au nom du pére. Une histoire de la paternité. Le Rocher 1987, págs. 71 y 77 . 


\section{MAGIA Y MEDICINA}

El pensamiento historicista de finales del pasado siglo XIX intentó ver el nacimiento de la medicina en los términos de una evolución en el sentido darwiniano. Según Hofschlaeger ${ }^{27}$, la medicina nació del sentimiento instintivo del hombre a curarse. $Y$ el hombre, una vez que estuvo ya en posesión de instrumentos, se serviría de los adecuados para evitarse el dolor de las heridas y sobre todo de las picaduras de insectos y reptiles y de las heridas producidas por ellos.

El hombre primitivo entendió la enfermedad como la introducción en el organismo de un cuerpo extraño, que puede extraerse, si es un ectoparásito, bien por succión, bien haciendo presión o con una sencilla operación, como puede ser una ligera incisión o levantar la costra con algo punzante.

Cuando la enfermedad es interna y se desconoce la naturaleza y la localización de ese cuerpo extraño, se hace lo mismo, pero de una manera simbólica, mediante un proceso mimético que representa plásticamente la extracción. De aquí arrancan las danzas y los cantos medicinales que son el más antiguo precedente del exorcismo.

Cuando del preanimismo se pasa al estadio animista, se identifica la enfermedad con un espíritu, al que se intenta expulsar por medio del exorcismo. Y este concebir los métodos terapéuticos como una acción expulsatoria es algo tan arraigado en la metalidad del hombre, que hasta la misma medicina hipocrática se basa en la creencia de que los agentes farmacopéuticos favorecen la expulsión de la materia peccans.

Para Ackernecht ${ }^{28}$, de este modo se hace una historia de la medicina empírica químicamente pura, anterior en su origen y paralela en su evolución a la medicina sacra y a la medicina mágica.

Pero dejando aparte los diversos procedimientos de adivinación empleados para el diagnóstico de las enfermedades, los principios en que se basa la medicina de los pueblos primitivos están, como reconoce $\mathrm{Ch}$. Coury, muy cerca de los principios mágicos ${ }^{29}$. Antes de la fase animista,

\footnotetext{
${ }^{27}$ GlL, L., Therapeia, pág. 23.

${ }^{28}$ ACKERNECHT, "Natural Diseases and Rational Treatment in Primitive Medicine", BHM XIX, 1947, págs. 467-497.

${ }^{29}$ Coury, $\mathrm{CH}$., "The Basic Principles of Medicine in the Primitive Mind", MH XI, 1967, págs. $11-127$.
} 


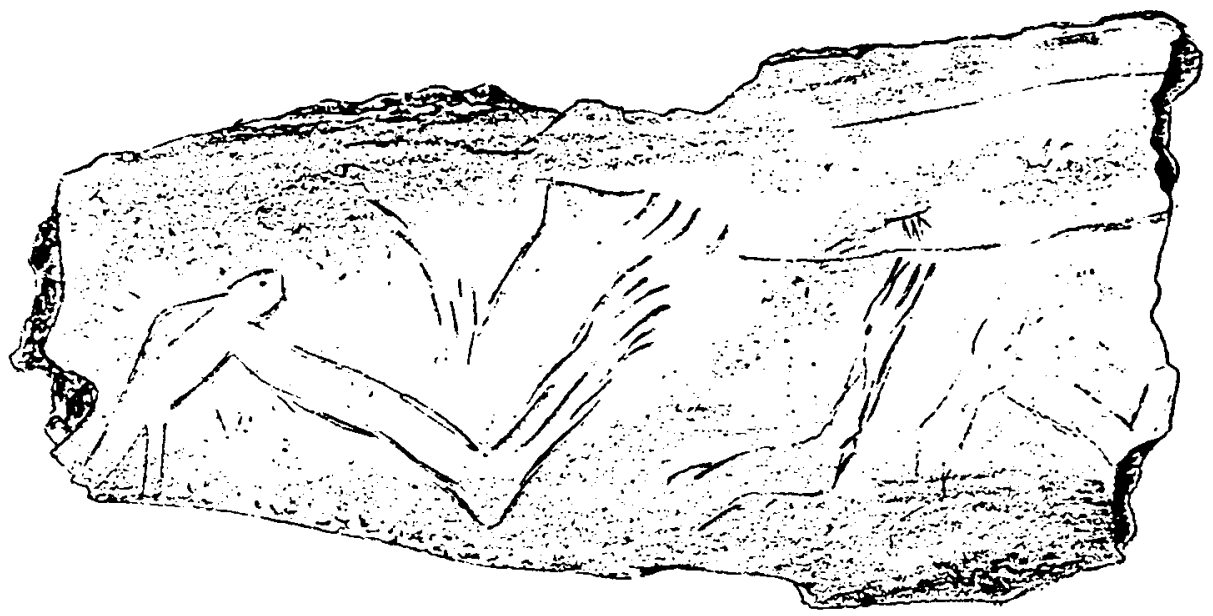

Fig. 5. LAUGERIE BASSE (Dordoña): Fragmento de omóplato con grabado que muestra la captura mágica de un pez. Dibujo tomado de Girod y Massénat, 1900. Sg. Geidión.

el hombre primitivo tiene una vaga noción de "fuerza", de carácter más - menos material (el "mana" al que nos referimos en otro lugar), que emana de las cosas de un modo espontáneo o provocado por la acción del mago. Estas fuerzas tienden a transmitirse por contacto y entran en relaciones mutuas de atracción y repelancia (similia similibus, contraria contrariis). De ahí la práctica de remedios homeopáticos y las curas por contrarios.

El contacto con estas fuerzas, algunas maléficas y opuestas a la naturaleza humana, produce la enfermedad, que puede lavarse y disolverse por medio de procedimientos purificatorios y elementos catárticos, como el agua. A veces se curan con plantas, de las que se tenía un conocimiento empírico, a cuyas virtudes se añadía el empleo de las pa-

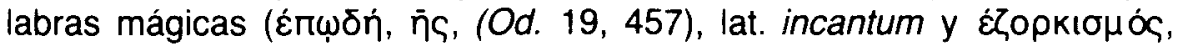
oū, lat. exorcismus), sobre las que nos extenderemos más adelante).

La extracción de la enfermedad se hacía por vía de contagio a otra persona o a un animal (transferencia y sustitución). Como profilaxis se empleaban amuletos, talismanes y fetiches, que transmiten su fuerza a quienes los porta y rechazan la de la enfermedad.

Desde las épocas más remotas, junto a la medicina empírica en principio, luego técnicas, de carácter profano, hubo el otro tipo de medicina al que nos hemos referido, la ritual y mágica, ejercida por hombres 
de características muy complejas. Si en la prehistoria del pueblo griego cabe imaginar la existencia de herboristas, antecesores de los рıцот ó $\mu$ ol o "corta-raices" de la época histórica, como en otras sociedades primitivas, desde los documentos más antiguos se perfila en Grecia la figura del iatpós, oū o "curador». La mención más antigua de la profesión médica corresponde a una tablilla de Pilos (PY Eq 146-49) en la que aparece un i-ja-te en posesión de tierras, lo que demuestra no sólo su elevado status social, sino también la distinción de sus funciones con

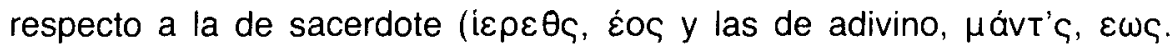
Desde la época micénica no se dieron en Grecia estas interferencias de atribuciones que había en Babilonia, donde los "conjuradores" (asipu o masmasu), aparte de sus demás cometidos rituales, se empleaban contra el demonio de la fiebre (Labartu) o en Egipto, donde la medicina fue competencia de la casta sacerdotal. Pero la medicina mágica fue ejercida

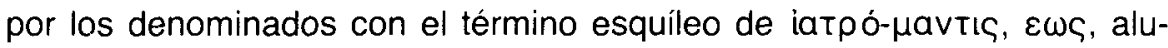
sivo a su doble naturaleza y para la época tardía el de "hombres divinos"

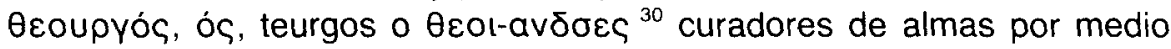
de la fuerza divina o "mana" que pasa a través de él. Estos continuaron actuando a lo largo de los siglos, con importancia social y personal variable, según las distintas épocas.

Inexistentes o silenciados en los momentos de ilustración, adquirieron un singular relieve en las épocas de angustia o crisis, cuando enfermos como Elio Arístides (siglo \| d.C.) se sometían a tratamientos increibles prefiriendo a la actuación racional del médico la acción directa en su persona de lo numinoso. Un Simón el Mago, un Apolonio de Tiana en el siglo I d.C. y un Alejandro de Abonutico en el siglo $\|$ d.C. son los más genuinos sucesores de los "chamanes" griegos de época arcaica.

Ahora bien, habida cuenta la similitud en las operaciones de quienes manipulaban las ciencias ocultas y las de los "hombres divinos", en la práctica era muy difícil trazar una división entre ambos. L. Gil señala cómo términos tan desagradables en su significación como ooplotŕs, oú, se revalorizan en los papiros mágicos (PGM IV 157) en la acepción más elevada de "sabio" y a la inversa, cómo Platón utiliza irónicamente

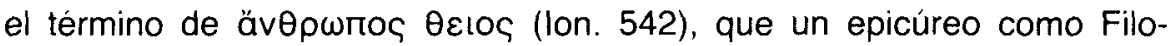
demo, emplea en su acepción más popular. Vemos pues que la gama de matices entre vidente, mago, profeta, sabio y portador de mana era tan sutil y variada que a veces eran similares para el vulgo.

30 JAMBL. Myst. 21 GIL, L., Obra citada pág. 76 y ss. 

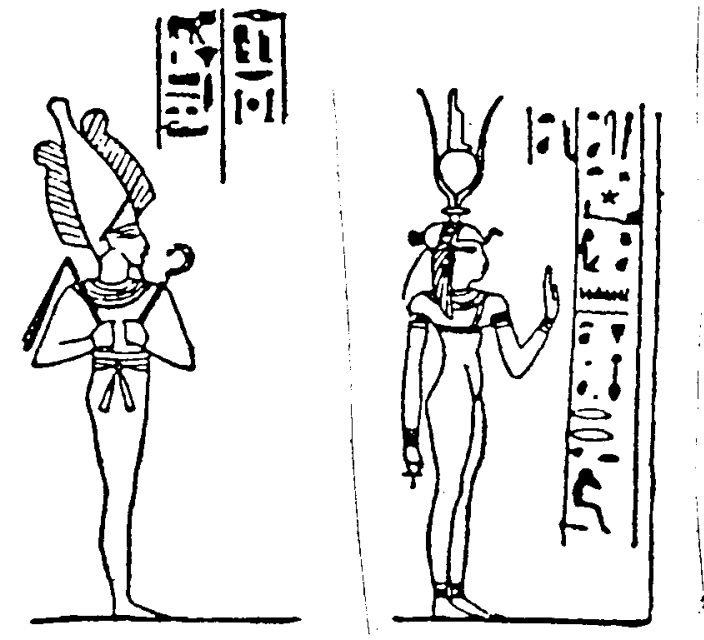

Fig. 6. Osiris, dios de los muertos. Isis, diosa de la magia.

\section{CLASES DE MAGIA}

Además de las arriba expuestas, se distinguen, entre los entendidos, varias clases de Magia:

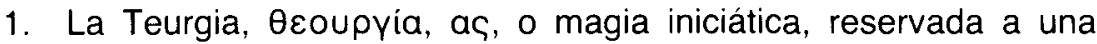
élite de adeptos, elegidos entre los miembros de las asociaciones dedicadas al estudio de una ciencia superior. La palabra Teurgia es griega y está compuesta por las palabras theos, $\theta \varepsilon$ ó (dios) y épyov (obra, trabajo). La expresión "teurgia" tenía dos sentidos: El de "acto del poder divino" y la de "puesta en acción de ese mismo poder". La práctica teúrgica tiene, por sus características, un carácter secreto y es casi desconocida, exige al que la practica aptitudes casi excepcionales y un alto nivel de conocimiento, que se adquiere con una profunda y prolongada preparación. Los que la practican son los teurgistas, a los que los antiguos griegos llamaron Énónths, ou (PLUT. Alc. 22) y a los que los hebreos conocian como «Reyes Magos». En la época clásica, la palabra "teurgia" se encuentra empleada en S. Agustín en el sentido de evocación de los espíritus. Esta clase de magia era considerada en Roma al mismo nivel que la religión y la filosofía ${ }^{31}$, demostrando Apuleyo la ne-

${ }^{31}$ Apul, Apol. XXVI, 1-3; XXVII, 1-2; sobre la magia en Apuleyo cfr. HIDALgo, M ${ }^{\mathrm{a}} \mathrm{J}$. , 
cesidad que todo filósofo tenía de conocer tales prácticas. Y la filosofía era una de las ciencias que formaba parte de la educación y formación de todo buen ciudadano ${ }^{32}$. Para Apuleyo, el mago es aquél que tiene un profundo conocimiento de la ciencia, practica las reglas y las disposiciones de la ley religiosa y los ritos del culto. Para constatar esta definición cita un texto de Platón sobre esta materia ${ }^{33}$.

2. La Alta Magia o Magia usual, a menudo confundida con la precedente, pero muy distinta, sobre todo en que los principios en los que está fundada, constituyen un conjunto doctrinal en el que el saber adquirido ordinariamente no está alejado más que en apariencia. La práctica de la Alta Magia requiere también unos conocimientos, a nivel físico y psíquico, para ser practicada con eficacia. Los que la practicaban recibían el nombre de "magistes", a los que los antiguos griegos llamaban uúotns, ou y los hermetistas de la Edad Media "Sabios" y se les conoce aún con el nombre de Magos.

3. La Brujería o Magia deformada, a la que la mayoría de los investigadores han tomado a menudo por la magia original, que, a menudo, se encuentra en contradicción con el saber ordinariamente adquirido y que no tiene en común con la Alta Magia más que el empleo de imágenes y prácticas, más o menos alteradas. Su práctica tiene también sus secretos, que se pueden entender fácilmente a veces. Sólo emplea los medios tradicionalmente transmitidos, a menudo poco o mal comprendidos. Para ella hacen falta pocos conocimientos intelectuales 0 psíquicos ${ }^{34}$. Su practicantes son los brujos, a los que los antiguos romanos confundian con los adivinos vulgares (ya vimos arriba la confusión entre los diversos términos, a los que se ha llamado "magos" o "fakires" hasta nuestros dias). La palabra MAG, en hebreo, tal vez relacionada con el asirio Mahu ${ }^{35}$ puede proceder de una tribu meda de origen no ario, de la que los Magos eran una casta sacerdotal.

4. Otra distinción de la Magia sería dividir la magia en «blanca» y "negra» o yonteía, ac, perseguida esta y castigada a nivel oficial, de la que en Roma dice Apuleyo ${ }^{36}$ :

"La magia y la religión en las obras de Apuleyo", Zephyrus 30-31, Salamanca 1980, págs. 223-230.

${ }_{32}$ APUL, Florid. IX, 1-2 y XVIII, 2-4-8; De deo Socratis XXIII.

${ }^{33}$ HIDALGO, $M{ }^{3}$ J., Obra citada, pág. 224. La teurgia se uniría íntimamente a la filosofía neoplatónica en época posterior a Apuleyo.

${ }^{34}$ PIOBB, Obra citada, pág. 18-20.

${ }^{35}$ Buisson, Obra citada, pág. 13.

${ }^{36}$ Apol. XLVIII, 3. 
Magia ista, quantum ego audio, res est legibus delegata, iam inde antiquitus duodecim tabulis propter incredundas frugum illecebras interdicta, igitur et occulta non minus quam tetrax et horribilis, plerumque noctibus uigilata et tenebris abstrusa et arbitris solitaria et carminibus murmurata.

Los ritos mágicos actuarían sobre los seres, visibles o invisibles, principalmente, según Buisson de tres formas o modos esenciales, dejando a un lado las variantes geográficas y étnicas de los diversos pueblos que la han practicado:

a) Por medido de la magia de encantamiento

b) Por medio de la magia mimética o de imitación

c) Por medio de la magia de amuletos, talismanes y pantacles.

"La magia de encantamiento" es la basada en el poder casi sobrenatural del canto, de la salmodia, de la repetición. En esta clase de magia, una fórmula de conjuro o imprecación posee la virtud de encadenar la voluntad de quien la pronuncia, hecha en las condiciones rituales precisas (palabra, ritmo, entonación), a los seres y las cosas del mundo de arriba y el mundo de abajo.

"La magia mimética" es la misma magia de encantamiento, en cuanto que recurre a la similitud.

"La magia de amuletos, talismanes y pantacles" es la que se sirve de estos objetos para sus fines

El término "amuleto" procede del latín amuletum, que Plinio utiliza para designar un objeto que protege a las gentes contra las enfermedades y que es una sustancia médica, que actúa tanto directa como indirectamente. Existe en él siempre un sentido profiláctico, ya que durante muchos años, maleficio, maleficium, fue siempre sinónimo de enfermedad $^{37}$.

Los amuletos, al menos en su origen, son vehículos de fuerzas místicas que proceden del mundo sobrenatural. El amuleto, en su estadio más elevado, es el "Talisman", término de origen incierto, que puede estar en la palabra hebrea tselem, imagen. Se encuentra entre los árabes bajo la forma de tilasm y tillams (plural talâsim, tilasmât y tilassamât).

37 GIL, L., Therapeia, citada pág. 162. RIVIĖRE, obra citada, pág. 14. 


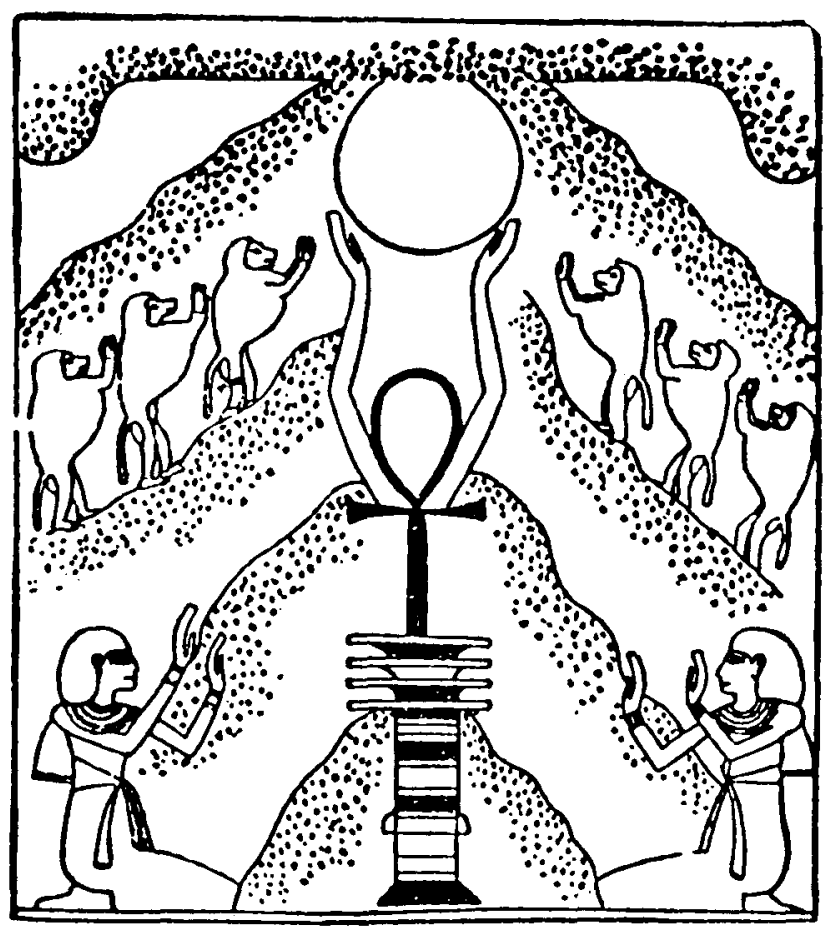

Fig. 7. Pilar DJED con simbolo de la vida encima y sol naciente en la montaña de la mañana. Egipto, de un papiro de la Dinastía XVIII. Neumann, pág. 244.

Su diferencia estriba en que, mientras que el talismán es artificial, aunque la materia con que se ha hecho sea natural, la influencia se le atribuye en función de un raciocinio, a veces lógico, pero siempre simbólico y analógico, mientras que el amuleto toma su substancia del mundo natural, animal o vegetal: cabello humano, espina de pescado, pluma, piel, concha, etc... cuya sola presencia detiene el mal.

La forma más evolucionada del talismán es el «pantáculo». Deriva de la palabra griega pan, todo, y procede de la idea de que es un objeto que lo contiene todo, que resume el "todo", siendo una síntesis del macrocosmos. Pero no es sólo un elemento protector como el amuleto, sino que es una especie de “emisor de fluidos", una potencia activa ${ }^{38}$.

38 Riviére, J., Amuletos, talismanes y pantacles. Barcelona 1974, pág. 14; LEVY-BRUHL, Le surnaturel et la nature dans la mentalité primitive. Paris 1957, pág. 32; ERNOUT, S., "La 


\section{LOS FENÓMENOS MÁGICOS}

El uso de la magia comprende diversos fenómenos mal determinados, ya que la extensión de la palabra magia es variable. En su empleo más restringido, desde el mundo clásico, significaría, como ya dijimos, la ciencia, la industria y la religión de los Magos, es decir, de los sacerdotes de la religión de Zoroastro importados a Grecia ${ }^{39}$, que fue tenida en ciertos momentos de la Historia como la más preciosa de todas las artes y la reina de las ciencias ${ }^{40}$.

Lo que pretende el mago, en términos generales, por medio de sus ensalmos y acciones rituales, es conocer, realizar y obtener aquello que por medios naturales no puede lograr un ser humano, porque lo impiden las leyes de la naturaleza. Por ello, su primer objetivo es superar esas leyes, para lo que sólo puede utilizar tres procedimientos:

1. Convertirse él mismo en un ser sobrenatural, tornándose inmortal, ya que solamente estos seres, de naturaleza extraordinaria, con poderes fuera de lo normal, pueden romper el orden natural. Esta inmortalización del mago consiste en su "solarización», es decir, en la unión (systasis) fortalecedora con la divinidad solar y otras veces toma el aspecto de una iniciación mistérica. Este es el caso de la "Liturgia de Mitra", con la que el mago se inicia en los misterios para convertirse en inmortal y, tras un viaje por el mundo cósmico, ya puede enfrentarse cara a cara con el dios supremo y allí aprender "su verdadero Nombre», el Nombre que no se puede pronunciar, es decir: alcanzar el conocimiento supremo y el poder supremo, puesto que conocer el nombre secreto de dios significa poder dominarle, llegar a destruirle $y$, por tanto, obligarle a actuar según convenga al mago.

II. Una segunda forma de romper las barreras de las fuerzas de la naturaleza es conseguir que un dios, de naturaleza superior, se ponga directamente al servicio del mago, ya sea indirectamente, a través de un ser intermedio, demon, ángel o arcángel. Ésto sólo puede conseguirse a

magie chez Pline l'Ancien", Col. Latomus LXX (Hom. a J. Bayet), págs. 190-195. VAzQuez HoYs, A. $\mathrm{M}^{\mathrm{a}}$, "Aspectos mágicos de la Antigüedad", Boletín de la Asociación de Amigos de la Arqueología núm. 19, Madrid, junio 1984, págs. 50-53, nota 6.

${ }^{39}$ Buisson, Obra citada, pág. 13; VazQuez Hors, A. M", "Aspectos mágicos de la Antigüedad", Boletín de la Asociación de Amigos de la Arqueología 19, junio 1984, págs. 5053.

${ }^{40}$ Cumont, F., Les religions orientales dans le paganisme romain. Paris 1929, pág. 151. 
través de la utilización de objetos o palabras mágicas que puedan obligar al dios a obedecer a un ser inferior.

III. $Y$, finalmente, el procedimiento más corriente suele ser el obligar a uno de estos seres intermedios inferiores, demon o ánima (a veces de un difunto muerto en circunstancias especialmente dramáticas), a que se ponga al servicio del mago. Ésto se consigue con la utilización de fórmulas mágicas, que aterrorizan a los demones o seres inferiores, ya que sus palabras les obligan inexorablemente, bajo terribles amenazas ${ }^{41}$.

\section{UNIVERSALIDAD DE LA MAGIA}

La magia la encontramos a lo largo de la Historia en todos los pueblos ${ }^{42}$ en los que la fe en los presagios y en las predicciones sobre el porvenir era general. El mundo primitivo que la vio nacer era el de las concepciones animistas, un mundo donde todos los seres animados e inanimados, hombres y dioses, estrellas, árboles, fuentes y roca se encerraban por igual un alma, un espíritu o, más exactamente, muchas almas $^{43}$. La creencia de nuestra civilización en la existencia en el hombre de una sola alma, de la unidad y permanencia del "yo", creencia que, desde luego, dista mucho de ser universal, nos hace difícil, a veces, entender la concepción animista que se halla en el origen de la magia. La constatación de la diferencia radical entre una persona viva y muerta, la gran pregunta de qué es lo que un momento antes de la muerte "animaba" al cuerpo vivo, que le "abandona" en su último suspiro, las apariciones en sueños de las personas muertas a los vivos y el mismo cariño de los seres vivos que se niegan a dejar desaparecer de su mente y de su vida a las personas queridas, debió dar origen a unas creencias

${ }^{41}$ Textos de magia en papiros griegos. Ed. Gredos. Biblioteca Clásica Gredos núm. 105. Introducción, traducción y notas de Calvo Martínez, J. L. y Sanchéz Romero, M. ${ }^{a}$ D. Madrid 1987, págs. 25-26. En general, cfr. una bibliografia más detallada en Cardini, F., Magia, citada, págs. 123-160.

${ }_{42}$ Cumont, Obra citada, núm. 1: Bibliografía muy completa sobre Astrologia y magia hasta su época. Cfr., asimismo, la nota 74 de la misma obra, pág. 292.

${ }^{43}$ Tokarev, S. A., Historia de las Religiones. Ed. Akal Bolsillo 1979. En la introducción se hace un breve estudio sobre la historia del desarrollo de las investigaciones sobre la religión y sus origenes en la ciencia premarxista y burguesa, analizando, entre otras, la obra de Tayior: La cultura primitiva, en la que expone la teoría animista (1871), que ganó rápidamente una gran popularidad entre los científicos de todos los paises y significó, según el mismo Tokarev reconoce, un importante paso adelante en el estudio de la religión (pág. 23). 
universales de la existencia en el Más Allá, al mismo tiempo que seguian queriendo ver en los objetos y lugares donde sus allegados habian vivido su presencia espiritual, recabando su intercesión y su ayuda ante las divinidades en el otro mundo ${ }^{44}$.

Según Taylor, esta fe surgió debido al interés peculiar que sentía el hombre primitivo ante estos estados especiales que sentía de vez en cuando el mismo hombre y quienes le rodeaban: Los estados de sueño, el desmayo, las alucinaciones y hasta la propia muerte.

Cuando los Egipcios, ya convertidos al cristianismo, hablan del alma,

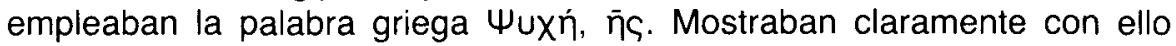
que ninguno de los términos empleados en su lengua se adaptaban claramente para definir sus creencias, sus nociones sobre la idea cristiana de alma.

En el más antiguo estadio de la Religión egipcia, que conservamos gracias a la compilación de los más antiguos textos religiosos egipcios,

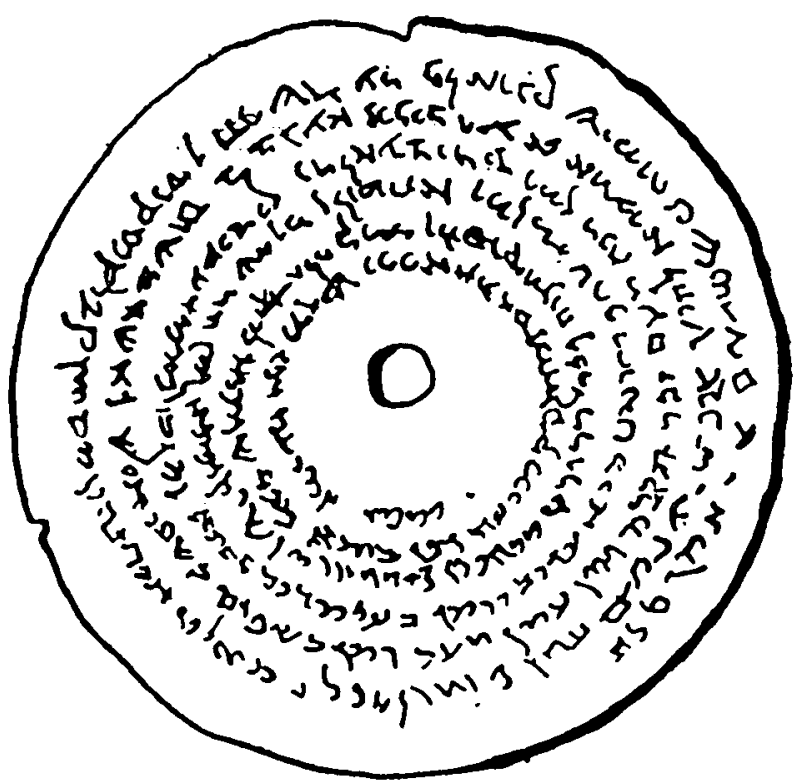

Fig. 8. Vaso mágico de protección encontrado en las excavaciones babilónicas. Según Buisson, pág. 63.

44 Tokarev, S. A., Historia de las Religiones, Ed. Akal bolsillo, 1979. Introducción. 
los llamados Textos de las Pirámides ${ }^{45}$, había ya tantas almas como centros de actividad se percibian en el cuerpo humano:

a) El $k a$, en el que algunos han querido ver un reflejo inmaterial del cuerpo, el doble, que reproducía la imagen del cuerpo y que recobraba su vida propia al morir el cuerpo físico, pero no podia tener entidad propia sin la existencia del soporte físico, como la momia o la estatua del difunto y del que otros hablan como del genio protector que nacía con el hombre, que vivía con él y que cuidaba del hombre hasta su muerte.

b) el ba, o "alma-pájaro", que la muerte tiene aún en sus brazos en las pinturas funerarias, algunas veces en forma de pájaro con cabeza y brazos humanos y presentando a la momia una vela, jeroglífico del viento y el aliento. Es la parte espiritual del individuo que, después de la muerte, encuentra su individualidad y puede errar a su antojo. Que puede quedarse en la cámara funeraria, al lado de la momia, pero que prefiere, sobre todo, pasearse por el cielo y volver a los lugares donde el difunto vivía, siendo a su vez, el alma itinerante de un ser viviente, capaz de acción material.

c) Otros de sus principios espirituales era expresado por medio del ibis con cresta, era el akh, un principio inmortal, "el luminoso", de la misma esencia del fuego y los astros, que, al morir el cuerpo, iba hacia la región ígnea situada por encima del cielo.

45 Pirámide de Unas, V Dinastia. Estos textos, extremadamente antiguos, remontan, por lo menos por vía de la transmisión oral, hasta tiempos anteriores a la I Dinastía. Son compilaciones grabadas sobre los muros de los corredores y cámaras de las pequeñas pirámides de Saqqarah, que comprende textos litúrgicos y fórmulas relativas a la suerte del rey en el otro mundo. El rey, luego de su muerte, sube directamente al cielo, se vuelve semejante a los dioses y vive eternamente en su compañia. El rey es divinizado, no por voluntad de los dioses, sino por su propia iniciativa; no es recibido en el cielo con benevolencia sino que está obligado a conquistar el cielo. Una vez admitido, lleva una existencia agradable, acompaña en la barca al dios-sol Re y se pasea a su gusto por los diferentes campos que componen el paraíso egipcio. Estos textos, empero, son una colección carente de unidad, de formulas cortas y primitivamente independientes unas de otras, tomadas de dos corrientes teológicas diferentes, una de Heliopolis, entre los sacerdotes del dios-sol Re y la otra de corte popular, derivada de las creencias osiríacas. La primera recensión conocida corresponde a la Pirámide de Unas, el último rey de la Dinastia V. Sobre la religión egipcia y sobre todo sobre lo que los autores antiguos, griegos y latinos escribieron sobre ella cfr. HopfNer, Fontes historiae religionis aegyptiacae. Bonn 1923-25. Una gran obra de conjunto es la de MASPERO, Études de mythologie et d'archeologie egyptiennes (Bibliothèque Égyptologique), París 1893-1912. Para una bibliografía general de la religión egipcia, sus dioses y los problemas de las interpretaciones de los textos, el monoteísmo etc... cfr. Drio. ton, E.-VANDier, J., Historia de Egipto. Ed. Eudeba. Argentina 1977, págs. 88-109 y 542 543. Sobre los textos de la Pirámides cfr. MERCER, The Pyramid texts in Translation and Commentary. Nueva York 1952, 4 vols. 
El akh es un principio inmortal y a la misma raiz corresponden las palabras "brillar" y "ser eficaz". Y parece que hay que ver en el akh un poder invisible que puede prestar su eficacia a los hombres y también a los dioses. En algunos contextos, akh se aplica a los "espíritus", genios intermediarios entre los dioses y los humanos. Algunas veces, designa a los muertos privilegiados o tal vez a los fantasmas o aparecidos, entre los Coptos, los akhou, en otros tiempos seres prestigiosos, que se convierten en “demonios" ${ }^{46}$.

Al lado de estos principios, ka, ba y akh, que se unían al cuerpo para formar un ser completo, la personalidad de un egipcio contaba aún con otros elementos, como la sombra negra que salía por las noches de la tumba o "Khaibit", y el "nombre", la esencia misma de la persona, su fuerza, que se mantenía en secreto, del que nos ocuparemos más tarde. Tal vez estos principios coinciden con la afirmación de Diógenes Laercio cuando dice:

“Todo el aire está lleno de almas, y éstas se consideran démones y héroes y por ellos les son enviados a los hombres los ensueños, las señales y las enfermedades, y no sólo a los hombres, sino a las ovejas y demás animales. Con respecto a ellos se han producido los ritos purificatorios y apotropaicos, toda la mántica, los rumores y las cosas semejantes" ${ }^{47}$.

En la civilización egipcia, llena de creencias en las fuerzas sobrenaturales, la magia se distinguia mal, tanto de la práctica de la religión como de la ciencia o la medicina. $Y$ no es en los templos o en sus representaciones donde se encuentran testimonios.

El culto oficial mencionaba, en ocasiones, la magia, como una ciencia legítima, enseñada y practicada por los dioses, pero no estaba fundamentada sobre ella. En la religión funeraria sucedia todo lo contrario. Su punto de partida estaba fundamentado sobre un conjunto de fórmulas y ritos mágicos compuestos por los sacerdotes de Heliópolis, que tendia a reformar el orden establecido en el otro mundo por medio de encantamientos irresistibles e incluso de amenazas. El procedimiento, heredado sin duda de usos prehistóricos, permaneció en las prácticas funerarias desarrolladas ulteriormente y su espiritu penetró usos que, como la momificación y las fórmulas funerarias, no habian sido mágicos en su origen.

\footnotetext{
${ }^{46}$ Dictionnaire de la civilisation égyptienne, sous la direction de POSEnER, G., Ed. F. Hazan. París 1986, pág. 9, s.v. “âme».

${ }^{47}$ DIOG.LAERT.VIII 32.
} 
En cuanto a la vida diaria, al lado de operaciones mágicas consideradas criminales, como la hechicería, se usaba sobre todo una magia profiláctica contra espíritus malignos, los animales dañinos, las enfermedades o el mal de ojo. Esta magia actuaba sobre todo por medio del recitado de fórmulas mágicas, por el poder de los nombres mágicos, por encantamientos, figuras y pinturas mágicas y por la posesión de amuletos que representaban dioses o sus emblemas, o por medio de la posesión de signos jeroglíficos que anotaban el nombre de los bienes cuya posesión se quería asegurar, todo acompañado de ceremonias y sobre todo de las poderosas palabras mágicas, que producen resultados sobrenaturales ${ }^{48}$, puntos estos sobre los que volveremos más tarde (continuará).

48 Sobre la magia en Egipto cfr. LEXA, La magie dans l'Égypte antique, 3 vol. París 1925. Sobre la magia greco-egipcia HOPFNER, Griechischägyptischer Offenbarungszauber. Leipzig 1921. Sobre los amuletos, cfr. WIEDEMANN, Die Amulette der Alten Aegypter. Leipzig 1910. También Ghalioungul, P.: Magic and Medical Science in Ancient Egypt. London, Hodder and Stoughton 1963; BuDgE, E.A.W., Egyptian Magic. Rutledge \& Kegan Paul, London, Boston and Henley 1899, reprinted in 1986. 